\title{
IMPROVING DENTAL HEALTH - IS IMPROVING QUALITY OF LIFE
}

DOI: 10.36740/WLek202103229

\author{
Nataliia I. Zhachko ${ }^{1}$, Tamara S. Nespriadko-Monborgne ${ }^{2}$, Iryna L. Skrypnyk ${ }^{1}$, Maksym S. Zhachko ${ }^{3}$ \\ 'DEPARTMENT OF ORTHODONTICS AND PROPEDEUTICS OF PROSTHETIC DENTISTRY, BOGOMOLETS NATIONAL MEDICAL UNIVERSITY, KYIV, UKRAINE \\ 2DEPARTMENT OF PROSTHETIC DENTISTRY, BOGOMOLETS NATIONAL MEDICAL UNIVERSITY, KYIV, UKRAINE
}

\begin{abstract}
The aim: To assess the impact of dental status on the quality of life of the adult population in the presence of periodontal disease in combination with musculoskeletal dysfunction in patients with dental anomalies and deformities.

Materials and methods: To study this goal, we examined 283 patients who complained of an aesthetic defect of the dentition, combined with the presence of joint pain and periodontal disease of varying severity.

Results: received a complete analysis of factors that significantly affected the quality of life of patients with a lot of diseases of the oral cavity.

Conclusions: Oral health deficiencies reduce the quality of life of our patients, and the treatment significantly changes its quality depending on age, sex and method. But the best results in achieving positive changes in the quality of life of the patient dentists can expect only by conducting a comprehensive treatment.
\end{abstract}

KEY WORDS: quality of life, dental health correction

Wiad Lek. 2021;74(3 p.ll):722-725

\section{INTRODUCTION}

Quality of life of the population is one of the generally accepted and important indicators that define the real opportunities of people that they need for a comfortable life. The characteristics of quality of life include all living conditions, factors and problems.

The search for and development of methods for determining the quality of life is an urgent problem of foreign and domestic medicine and the state of dental health is given a very important role [2].

Dental or oral health includes a condition that allows a person to eat, improve communication, restore the aesthetic function of the mouth and face, and increase self-esteem [3].

In the 1980s, Reisine S.T. drew attention to the impact of pathological conditions in the oral cavity on human social and psychological well-being, which was the impetus for the development and implementation of tools for measuring the quality of life associated with the state of dental health [4].

In studying the state of the problem from the point of view of dental health, 4 types of factors were identified that are directly related to the quality of life of patients:

1. Pathology of the dental-maxillary system, which quantitatively and qualitatively affect on quality of human nutrition;

2. The state of the dental-maxillary system that affects on communicative function of man;

3. Influence of the condition of the dental-maxillary apparatus, which affects on aesthetics of the face and smile;

4. The condition of the dental-maxillary apparatus, which affects on them function.

An important role is played by the maxillofacial area in the matter of human communication. Therefore, the most important areas and defects that are associated with the communication process - defects in the frontal area, smile, pronunciation changes, splashing saliva during conversation - all these signs accompany a number of abnormal processes, namely abnormalities in the location of individual teeth and occlusion can lead to joint trauma (acute, subacute: Nespryadko V.P., Tereshchuk O.G., Skrypnyk I.L.), which due to the pain symptom adds difficulties with prolonged chewing - especially in public places.

Therefore, it is clear that all these situations rapidly reduce the quality of life of people with similar problems and due to mass dental diseases: periodontal disease, dysfunction of the temporomandibular joint, occlusal pathology, can be considered as one of the important influencing the quality of life and gives the opportunity to search for us to improve it.

\section{THE AIM}

Therefore, the aim of our study was: to assess the impact of dental status on the quality of life of the adult population in the presence of periodontal disease in combination with musculoskeletal dysfunction in patients with dental anomalies and deformities. 


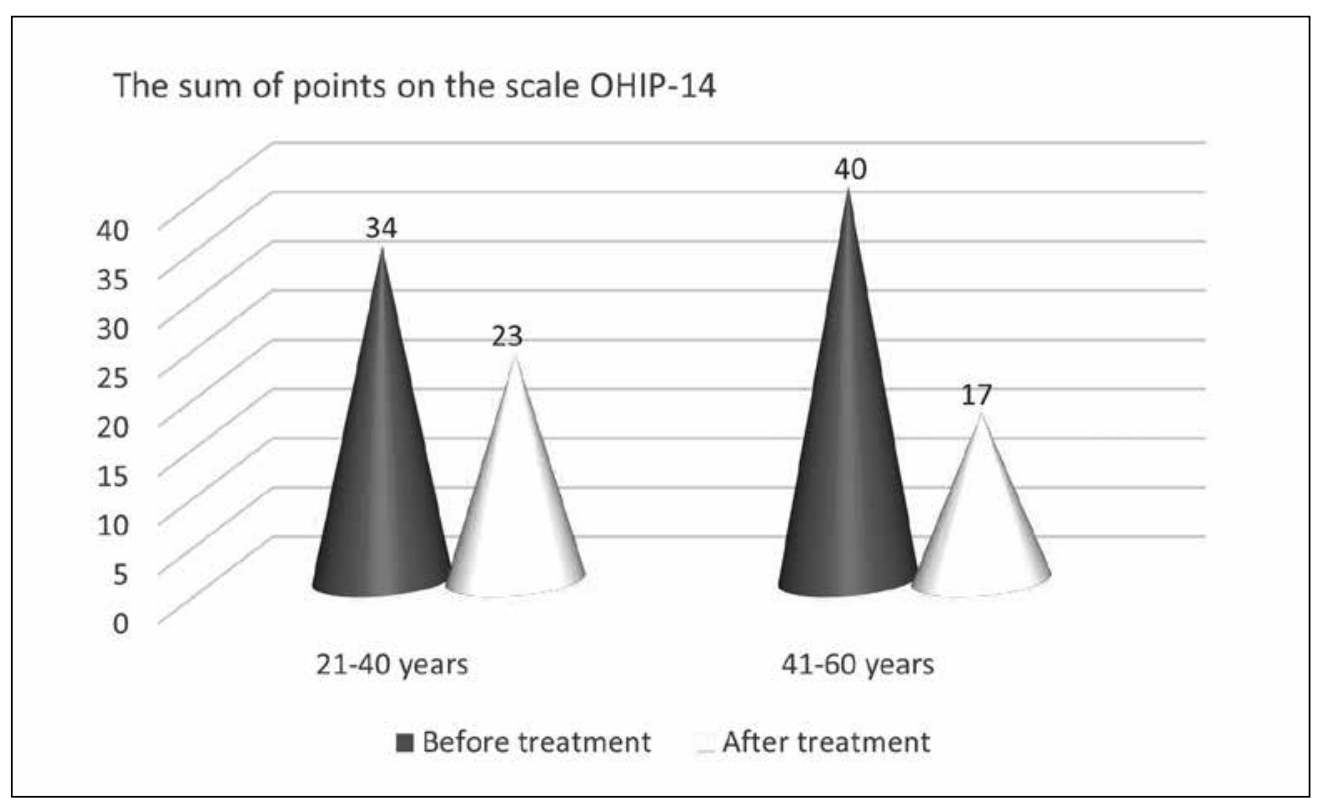

The sum of points on the scale OHIP -14

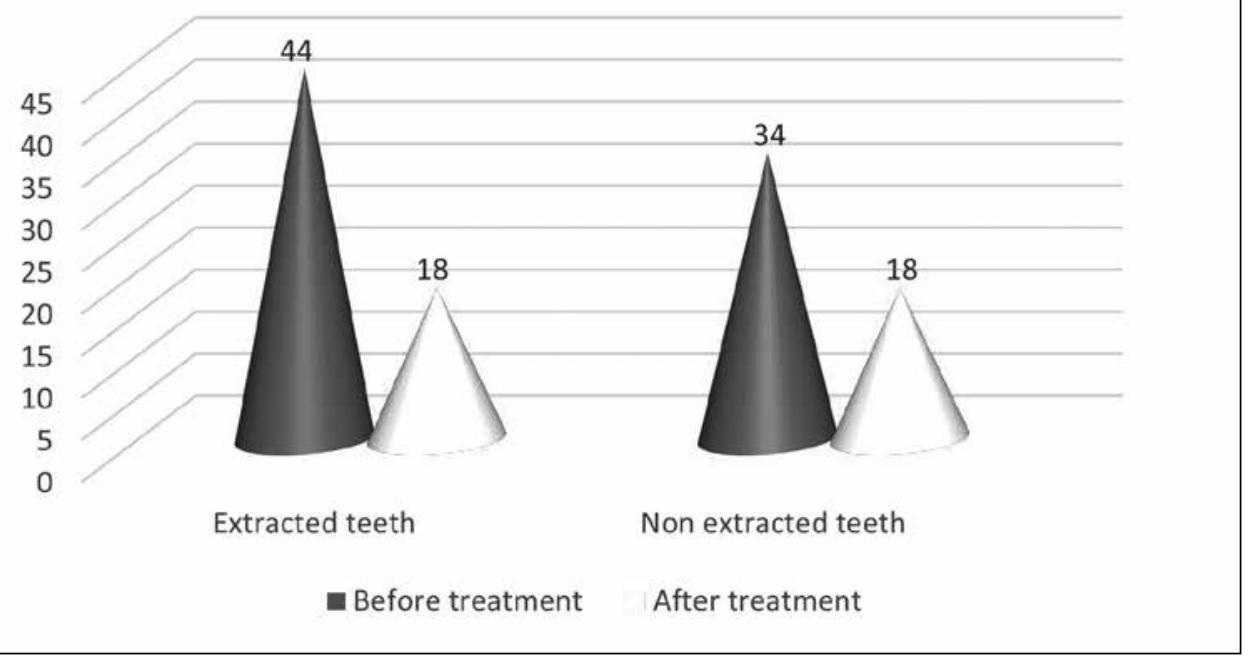

Fig. 1. Dependence of quality of life change from age, after correction of dental health.
Fig. 2. Changes in quality of life after correction of the TMJ (Temporomandibular joint).

\section{MATERIALS AND METHODS}

To study this goal, we examined 283 patients who complained of an aesthetic defect of the dentition, combined with the presence of joint pain and periodontal disease of varying severity.

All patients were called for a repeat visit after 6 months, but only 173 people showed up. The age of the subjects varied from 21 to 60 years, among them 83 men. All patients lived in Kyiv and Kyiv region.

Quality of life was examined by a special questionnaire with the degree of measurement on the scale OHIP-14 (The Oral Health Impact Profile) [1].

\section{RESULTS AND DISCUSSION}

After the treatment, which consisted of restoration of occlusion by gnathological preparation, prosthetic restoration of the destroyed areas in combination with orthodontic correction of anomalies and periodontal support?
During the analysis the results of a study on the quality of life related to food intake, concerns were expressed at the first visit, but it turned out that it was more psychological in nature. What really affected, first of all, the quality of life was the age of the patients.

In patients aged 21-41 years, the quality of life after dental treatment increased 1.5 times, while in older patients -2.3 times (Fig. 1).

I will note that before the start of treatment the quality of life of patients in the older group was the worst - after treatment - it became better.

The second social factor that significantly affects the quality of life after the aesthetic restoration of occlusion was gender. At the beginning of the examination, the difference in this feature was not detected, but 6 months after completion of treatment, the quality of life for men improved 1.6 times, and for women -1.9 - this is as in the previous case due to improved process food intake.

After the treatment, the quality improved to the highest extent, 2.5 times in those who underwent gnathological 


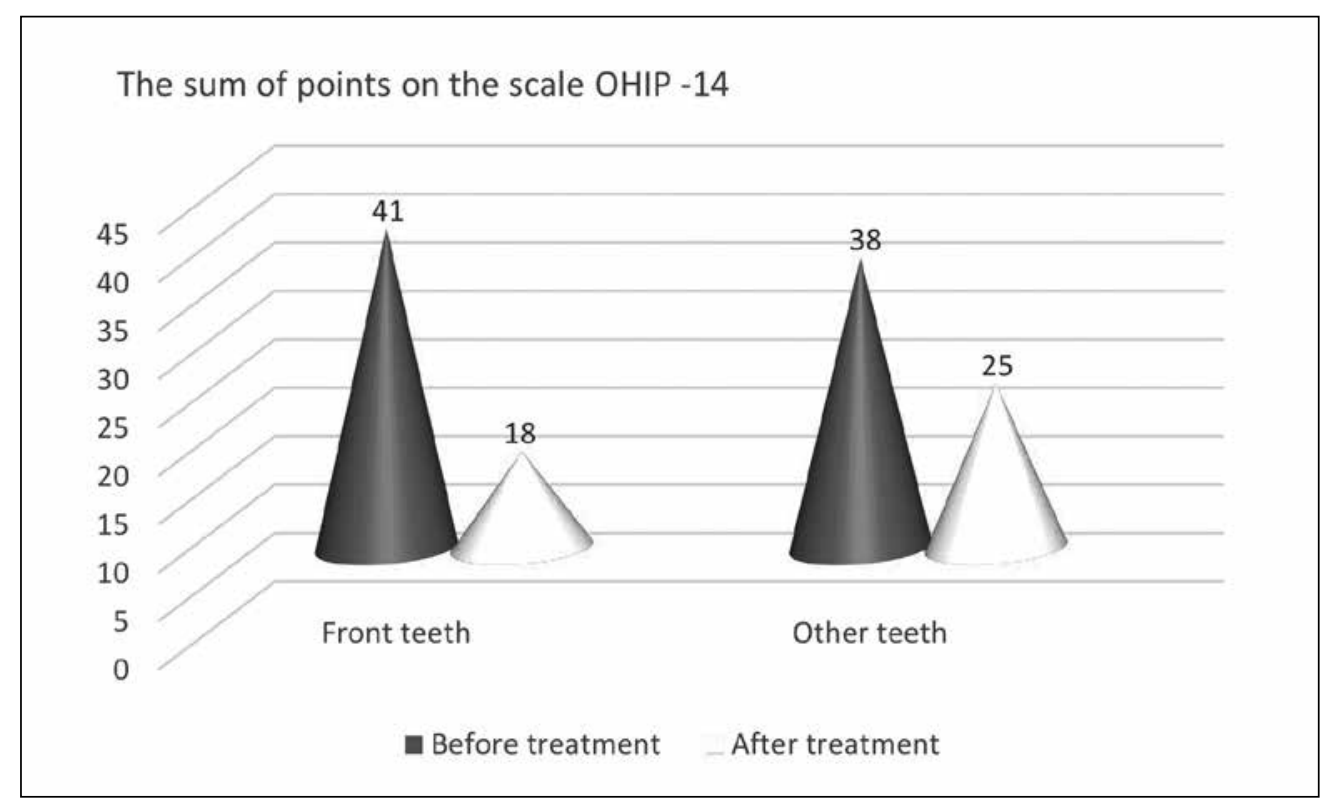

The sum of points on the scale OHIP -14

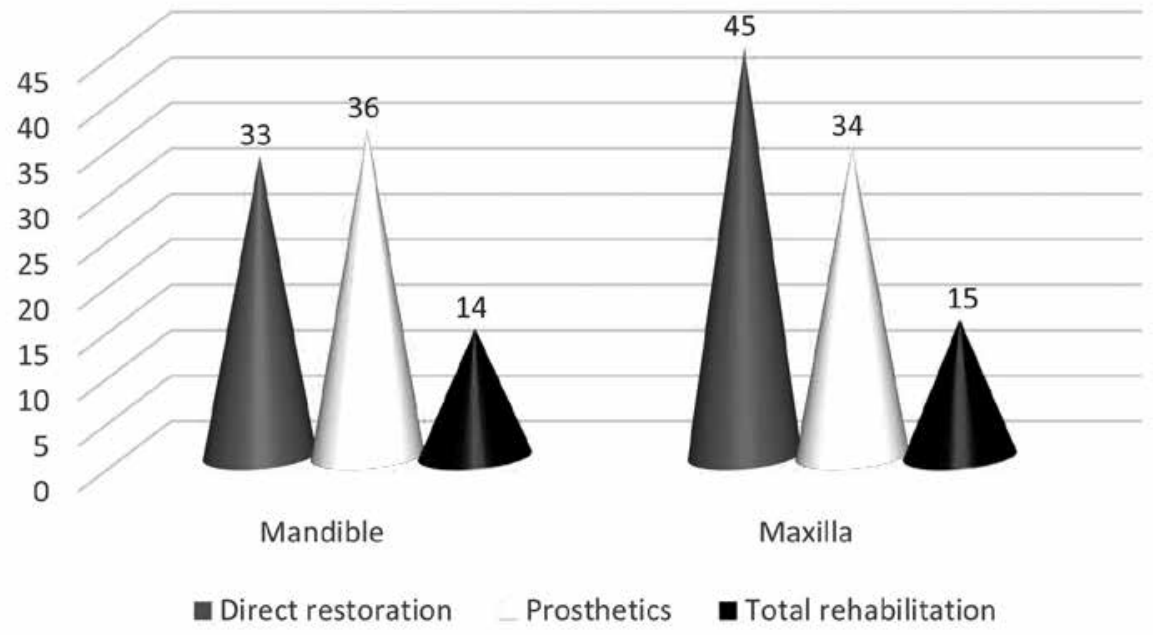

Fig. 3. Changes in quality of life depending on the location of the defect and occlusion anomaly.
Fig. 4. Changes in quality of life depending from the type of correction provided. stage with the help of splint therapy before the prosthetic stage, than those who underwent prosthetics and underwent orthodontic treatment without this stage - 1.9 times - and was not important it was only a relaxing or repositioning splint. At the initial examination, joint pain showed the worst quality of life (Fig. 2).

Another clinical factor influencing the quality of life was the localization of occlusion anomalies and abnormal location of individual teeth. When changing the appearance of the frontal area, the quality of life improved 2.3 times, while the latent (for the patient) manifestations of occlusion pathology in the presence of a problem in the lateral - improved 1.5 times as in other studies, the subjective feelings of patients (Fig. 3).

The next clinical factor influencing the quality of life was the type of treatment - namely, the best quality of life was found in the comprehensive rehabilitation of oral health, by periodontal and gnathological preparation before prosthetic restoration, with orthodontic correction. In addition to the medical advantage, he had the highest level of improvement in the quality of life of patients 2.5 times on the lower jaw and 2.7 times - on the upper jaw (Fig. 4).

\section{CONCLUSIONS}

Accordingly, it can be concluded that the deficiencies associated with oral health reduce the quality of life of our patients, and the treatment significantly changes its quality depending on age, gender and method. But the best results in achieving positive changes in the patient's quality of life dentists can expect only by conducting a comprehensive, pathogenetically justified - in this case consisting of periodontal treatment, orthodontic occlusion correction, gnathological preparation with subsequent prosthetic restoration of occlusal contacts, which also has long-term functional aesthetic result of treatment. 


\section{REFERENCES}

1. Vedeneeva E.N., Gurevich K.G., Vagner V.D. et al. Sochialnaya harakteristika i kachestvo zhizni patsientov, obrashchayushchihsya $v$ kliniku esteticheskoy stomatologii. [Social description and quality of life of patients circulating in the clinic of aesthetic stomatology] Kremlevskaya med. 2009; 2: 149-151. (In Russian).

2. Beskaravaynaya A.V., Ovodova G.F., Kuzmina L.N. Opredelenie faktorov, imeyushchih otnoshenie $\mathrm{k}$ kachestvu zhizni vrachey stomatologov. [Determination of factors, relating to quality of life of doctors of stomatologies]. Bul. Sev. gos. med. un-ta. 2008; 1: 138-139. (In Russian).

2. Opravin A.S., Ovodova G.F., Kuzmina L.N. et al. Professionalnaya deyatelnost vrachey stomatologov $v$ aspekte osnovnyh pokazateley kachestvu zhizni [Professional activity of doctors of stomatologies is in the aspect of basic indexes of quality of life]. Ekologiya cheloveka. 2008; 4: 16-18. (In Russian).

3. Greenstein G., Cavallaro J., Tarnow D. When to save or extract a tooth in the esthetic zone: a commentary. Compend Contin Educ Dent. 2008; 29: 3: $136-145$.

\section{ORCID and contributionship:}

Nataliia I. Zhachko: 0000-0001-5333-0191 A, B, D, E, F

Tamara S. Nespriadko-Monborgne: 0000-0002-3102-8634 ${ }^{\text {A, B, D, F }}$ Iryna L. Skrypnyk: 0000-00023-3393-4649 ${ }^{A, D, E, F}$

Maksym S. Zhachko: 0000-0003-4054-6211 A, C, D, E

\section{Conflict of interest:}

The Authors declare no conflict of interest.

\section{CORRESPONDING AUTHOR \\ Nataliia I. Zhachko \\ Bogomolets National Medical University \\ 13 T. Shevchenko blvd., 01601 Kiev, Ukraine \\ tel: +380964411448 \\ e-mail:2407@i.ua}

Received: 20.12.2020

Accepted: 05.03.2021

A - Work concept and design, B - Data collection and analysis, C - Responsibility for statistical analysis,

D - Writing the article, $\mathbf{E}$ - Critical review, $\mathbf{F}$ - Final approval of the article 